\title{
A Case of Giant Fibroid Uterus
}

\author{
IRIN PARVEEN ALAM ${ }^{1}$, RAFAT NEWAZ ${ }^{2}$
}

\begin{abstract}
:
Fibroids are muscular tumours, the most common benign tumours in females and typically found during the middle and later reproductive years. It originate from the smooth muscle layer of the uterus. Another medical term is leiomyoma or just myoma. It can be as small as an apple seed or as big as a melon. In unusual cases they can become very large. With the advent of high frequency ultrasonography and magnetic resonance imaging it is now possible to diagnose such cases at an early stage ${ }^{1}$. Asymptomatic uterine fibroids often left untreated. Giant fibroids are the fibroids weighing $11.4 \mathrm{~kg}^{2,3}$ or more. Such a fibroid may appear as a solitary tumor or as a conglomerate mass of uterine fibroids presenting as a single uterine tumor 4 .

Giant uterine fibroid are very rare neoplasm and represents a great diagnosis and therapeutic challange. This article illustrates a case of 34 years old woman presented with a four year history of slowly increasing abdominal size with rapid increase in the last one year associated with shortness of breath and severe anaemia by a painless lump. Total abdominal hysterectomy was performed; histologically the specimen was $9.5 \mathrm{~kg}$ benign uterine leiomyoma. The patients postoperative evaluation was uneventful and she went back abroad in two months time following operation.
\end{abstract}

Keywords: Leiomyoma, Giant fibroid uterus,

\section{Introduction:}

Uterine leiomyoma is a common entity. They are found in nearly half of women over age fourty; the privilege increases during the reproductive age and decreases after menopause ${ }^{5-9}$. But large fibroid now a days with advent of easy availability of ultrasonography is a rare condition. Major complications of myoma often relate to location of myoma. These tumours frequently causes abnormal menstrual blood loss, pelvic pain, and pressure symptoms. Fibroid tumors that are asymptomatic sometimes left untreated as long as no emergency arises. However, large uterine fibroids often creates surgical difficulties as it grows as a giant fibroid. A neglected and interesting case of a giant fibroid uterus is presented here.

\section{Case Report:}

A 34 years multiparous Bangladeshi woman, living in Spain presented in a private clinic of Bangladesh with a painless lump and gradual distension of abdomen for last 5 years. There was no history of nausea, vomiting, and loss of weight or appetite. There was history of bowel and bladder irregularity for last few months in the form of occasional constipation and increased frequency of micturition. Regarding menstrual history menarche was at 13 years and she noticed menstrual irregularity and menorrhagia for last one year. She was married for 16 years and was mother of 2 children delivered vaginally, age of last child was 9 years. She noticed a lump for last 4-5 years which was gradually increasing in size, and she consulted doctors of Spain, and was advised for laparotomy. But she refused

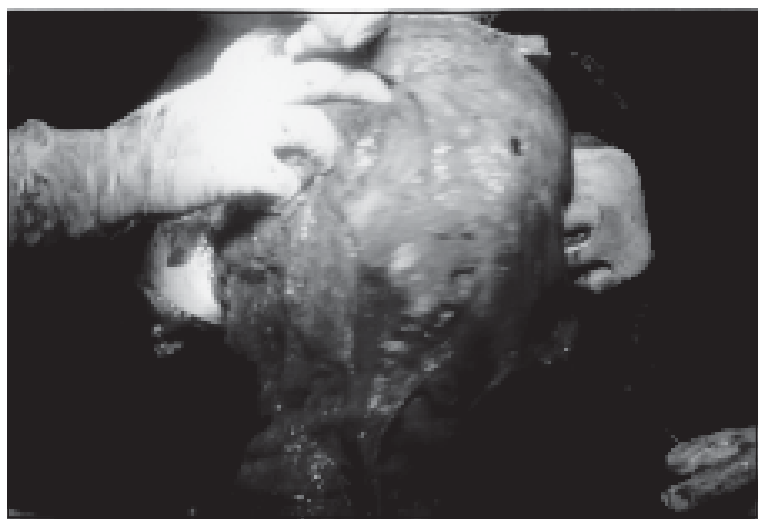

Fig-1: After partial myoma removal, the figure of uterus.

1. Assistant Prof Obstetrics \& Gynae, Faridpur Medical College Hospital, Faridpur,

2. Associate Prof Obstetrics \& Gynae. Bangladesh Medical College Hospital, Dhanmondi, Dhaka. 
to do that for fear and high cost of operation there. She took some homeopathy medicine for treatment; in spite of this the mass was gradually increasing in size. Her past medical, surgical and family history was not significant. She presented to this clinic as she noticed that over the past years the mass was growing more rapidly and she started to feel abdominal discomfort and shortness of breath. On physical examination, she was severely anaemic, had a grossly visible large fixed abdominal mass, which had extended up to the sternum. It was firm, non tender and non-tympanic and partly irregular. On pelvic examination, she had a posteriorly displaced cervix with no lesions or inflammation. Her shortness of breath was likely due to the elevated diaphragm and severe anaemia. Her hemoglobin level was $4.5 \mathrm{gm} /$ dl. USG abdomen showed huge soft tissue mass arising from uterus with partial cystic area, in different regions; her intravenous urography report was normal.

After correcting anaemia with 5 bags of packed cell, laparotomy was done. Right paramedian vertical incision was given. Uterus was hugely enlarged tightly occupying whole abdomen, some additional pedunculated fibroids were found to be arising from the fundus and body of the uterus posteriorly. Uterus was adherent posteriorly to the sacrum, occupying whole of the pelvis with restricted mobility. Fallopian tubes and ovaries could not be reached. Vertical incision was given in the uterus and multiple fibroids were removed to reduce the size of uterus. It was so big that even after removal of several fibroids, with two- three myoma screw, uterus could not be mobilized from abdominal cavity. Some myomas were necrotic and foul smelling. Some myomas showed cystic and degenerative changes. Most of

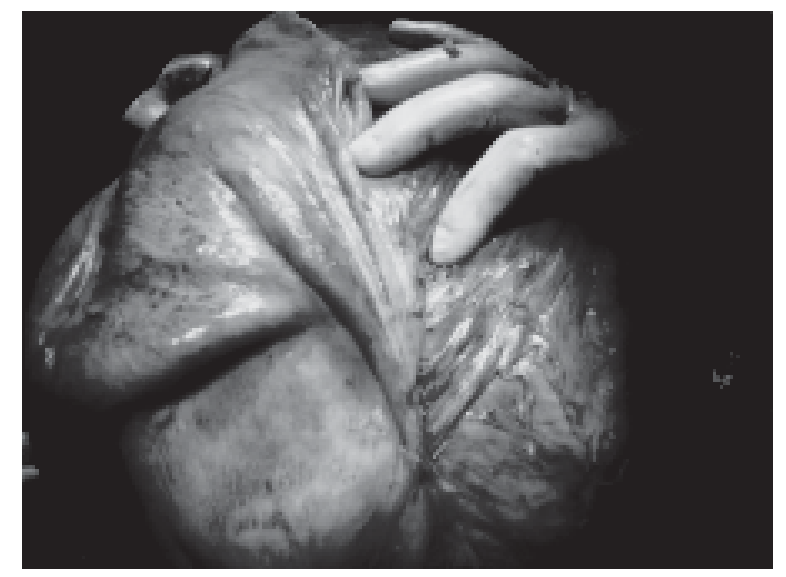

Fig-2: A big myoma separating from fundus of uterus. the myomas were intramural and pedunculated. After removal of several myoma fundus of uterus, fallopian tubes and ovaries were visualized. Right ovary was polycystic and diathermy cauterization was done,

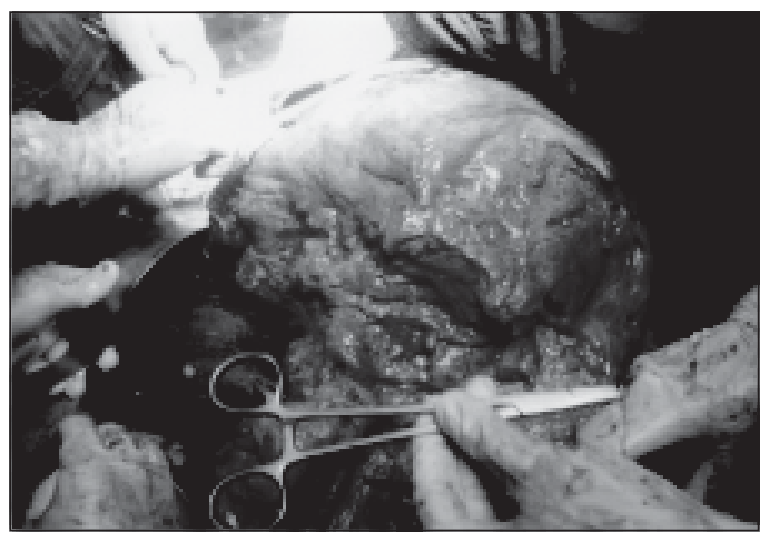

Fig-3: Part of necrotic tumour.

there was a cyst in left ovary about $5 \times 4 \mathrm{~cm}$ and cystectomy was done. As patient did not want to preserve uterus and tumor mass was irregular distorting whole uterine structure, total abdominal hysterectomy was performed. Operation was done with special attention to ureter of both side. The resected specimen was $9.5 \mathrm{~kg}$ in weight. As the tumour was with degenerative changes bleeding was not as heavy as assumed. Although bleeding was average three bags of blood transfusion was given during operation. Histopathology showed benign Leiomyoma of uterus. Patient had uneventful postoperative period and after 2 months she again went back abroad.

\section{Discussion:}

Leiomyoma/fibroma/fibroid is the commonest benign uterine tumour and accounts for the most common indication for hysterectomy ${ }^{10}$. They are usually diagnosed on physical examination. These tumours are present in approximately one-third of women of reproductive age ${ }^{11}$. Giant uterine fibroids are those weighing greater than $25 \mathrm{lb}(11.4 \mathrm{~kg})$ or diameter more than $17 \mathrm{~cm}$. or dimension $33 / 28 / 22 \mathrm{~cm}^{1,3,12}$. The tumour discussed here weighed $9.5 \mathrm{~kg}$. Giant uterine tumors are uncommon. These tumours frequently cause abnormal periods, pelvic pain, and pressure symptoms on surrounding organs. However, they may be life threatening because of pressure effects on the lungs, urinary bladder, ureters and other adjacent organs ${ }^{13}$. The case presented here, 
had at first no symptoms: so patient herself enjoyed expectant management and consulted with doctor when pressure symptoms started. Ultrasound is usually the initial screening tool for myomas. Since the advent of MRI scan, the precision for identification, number, and location of these tumors, as well as differentiation from an adnexal mass has increased, MRI has been judged to be the most expensive modality for evaluating fibroid tumors. Computed tomography (CT) scan has also been used as a tool to diagnose uterine fibroids. Now its role is limited to cases of fibroids with complications such as necrosis and malignant transformation ${ }^{12}$. In this case ultrasonography and Intravenous urography was done to note the position of ureters.

Degenerative changes in the leiomyoma are considered to be due to inadequate blood supply and degenerative changes seem to depend on the degree and rapidity of the onset of vascular insufficiency. The fibroid in our case report had undergone hyaline, cystic and myxomatous degeneration. There is no particular relationship between any symptom or group of symptoms and the incidence of degenerative changes $^{13}$.

The treatment options includes expectant management, surgery, uterine artery embolization, ablative techniques and medical management. Expectant management with observation is increasingly recognized as a reasonable course for women with asymptomatic small and large fibroid tumors. Medical management by prescribing gonadotropin-releasing hormone analogue has been used to suppress estrogen production, thereby reducing the size of existing myomas to make them amenable to laparoscopic surgery ${ }^{1}$. Even rapidly growing tumors should not be removed routinely because the risk of a malignant leiomyosarcoma is small $(0.23 \text { percent in one study })^{14}$.

Selected patients may benefit from surgery. Appropriate counseling and possibility of myomectomy are recommended in symptomatic patients as well as in those with large, asymptomatic tumors in an effort to preserve fertility and menstrual function in young patients. Long-term medical treatment is associated with high cost, menopausal symptoms, and bone loss, increased recurrence risk ${ }^{15}$.

Before surgery it is important to counsel the patients. This is needed because patients undergo an extreme amount of stress, anxiety, and depression when faced with such a big tumour. Discussing the low likelihood of malignancy will help to quell above feelings as well as assist in obtaining informed consent for surgery 16. Surgical removal of large uterine fibroids is the traditional treatment since they may cause infertility and in the presence of pregnancy they may affect the outcome ${ }^{1}$. For our patient, surgical management was needed. An exploratory laparotomy was the only method available due to the size of the mass. Huge tumors as seen in this patient pose a great surgical challenge. Combined preoperative and postoperative mortality rates of $14-16 \%$ were seen in giant fibroids in nonpregnant patients ${ }^{17}$.

Surgical removal of giant fibroids presents technical difficulties mainly due to massive blood loss caused by increased vascularity. There might be other technical difficulties and also carries increase risk of injury to ureter. Uterine Artery Embolisation (UAE), as a pre-surgical treatment to decrease intraoperative blood loss, was found to be effective in some studies. UAE was reported to be more costeffective than myomectomy and hysterectomy ${ }^{18}$. Embosphere Microspheres, the most clinically studied embolic, provide consistent and predictable results for effective embolization in the treatment of uterine fibroids, hypervascular tumors or arteriovenous malformations ${ }^{19}$. Myolysis including mono or bipolar cautery, Nd-YAG laser vaporisation or cryotherapy is currently experimental ${ }^{20-22}$.

\section{Conclusion:}

An atypical presentation of fibroids is often confusing to clinicians. A fibroid can grow to a large size as exemplified in this case. Different clinical manifestations can be expected in cases of giant uterine tumors according to which other organs are secondarily affected. Numerous difficulties may be encountered in the evaluation and removal of these tumors. A combined team consisting of gynecologic, general, and plastic surgeons is necessary for a optimum outcome.

\section{References:}

1. Karim $T$, Kundan P, Panchal A, Basu C, Presentation and management of giant fibroid uterus in an adolescent girl, Open Access surgery 2010:33 13-15.

2. Evans AT 3rd, Pratt JH. A giant fibroid uterus Obstet Gynecol. 1979;54(3):385-6. 
3. Savulescu F et al. Giant uterine leiomyoma. Chirugia. 2011;106(5): 665-668.

4. Oelsner G, Elizur SE, Frenkel Y, Carp H. Giant uterine tumors: two cases with different clinical presentations. Obstet Gynecol. 2003;101:1088-9.

5. Hoffman B. Pelvic mass. In: Schorge J, et al editors. Williams Gynecology, Chapter 9. 1st Ed. McGraw-Hill; 2008: p. 197-224.

6. Courbiere B. Carcopino X. Fibromes uterins. In: Gynecologie Obstetrique. 6th ed. Vernazobres-Greco; 2006-2007; p. 359-365.

7. Pitkin J. Uterine fibroids. In: Obstetrics and gynaecology. Ed. Churchill Livingstone; 2003. p. 118-119.

8. Jonas HS. Giant uterine tumors: case report and review of the literature. Obstet Gynecol. 1977;50 (1 Suppl):2s-4s.

9. Grapsa D. A giant uterine leiomyoma simulating an ovarian mass in a 16-year-old girl: a case report and review of the literature. Eur $\mathrm{J}$ Gynaecol Oncol. 2006;27(3):294-6.

10. Van Voorhis BJ, Romitti PA, Jones MP. Family history as a risk factor for development of uterine leiomyomas: result of a pilot study.J Reprod Med. 2002;47:663-669.

11. Fields KR,Neinstein LS.Uterine myomas in adolescents:Case reports and a review of the literature.J Pediatr Adolesc Gynecol. 1996;9:195-198.

12. Karim et al. A case of giant fibroid uterus in an adolescent girl. Calicat Medical Journal 2009; 7(4).

13. Yuel VI, Kaur V, Broad Ligament Fibroid - An Unusual Presentation JK Science 2006; 8(4): 217-218
14. Schwartz PE, Kelly MG. Malignant transformation of myomas: myth or reality? Obstet Gynecol Clin North Am 2006; 33: 183-98.

15. Kjerulff $\mathrm{KH}$, Rhodes JC, Langenberg PW, Harvey LA. Patient satisfaction with results of hysterectomy. Am J Obstet Gynecol 2000; 183:1440-7.

16. Amber I, Kennedy G, Martinez H, Pearson $\mathrm{JM}$, Jimenez E, A Leiomyoma in a Cachectic Woman Presenting as a Giant Abdominal Mass. Obstetric \& Gynecologic Radiology: 2009; 3(10):23-29.

17. Exacoustos $\mathrm{C}$, Ro sati P. Ultrasound diagnosis of uterine myomas and complications in pregnancy. Obstet Gynecol 1993; 82:97-101.

18. Bahri $\mathrm{U}$ et al, Is uterine artery embolization prior to myomectomy for giant fibroids helpful? Diagn Interv Radiol 2007;13:210 -212.

19. Kirsch RW, et al. The Fibroid Registry for Outcomes Data (FIBROID) for Uterine Embolization Short-Term Outcomes; Obstetrics \& Gynecology; 2005; 106(1).

20. Van Voorhis B. A 41-year-old woman with menorrhagia, anemia, and fibroids: Review of treatment of uterine fibroids. JAMA. 2009;301(1):82-93.

21. Corton M, Cunningham F, Gala R, Hoffman B. Aspect of gynecologic surgery. In: Schorge J, et al, editors. Williams Gynecology, Chapter 3840. 1st ed. McGraw-Hill; 2008: p. 773-865.

22. Donnez J, Squifflet J, Polet R, Nisolle M. Laparoscopic myolysis. Hum Reprod Update. 2000;6(6):609-13. 